\title{
BMJ Open Effect of sex and age on the association between suicidal behaviour and obesity in Korean adults: a cross-sectional nationwide study
}

\author{
Dae-Kwon Kim, ${ }^{1,2}$ Hyun Jin Song, ${ }^{1}$ Eui-Kyung Lee, ${ }^{3}$ Jin-Won Kwon ${ }^{1}$
}

To cite: Kim DK, Song HJ, Lee EK, et al. Effect of sex and age on the association between suicidal behaviour and obesity in Korean adults: a cross-sectional nationwide study. BMJ Open 2016;6: e010183. doi:10.1136/ bmjopen-2015-010183

- Prepublication history for this paper is available online. To view these files please visit the journal online (http://dx.doi.org/10.1136/ bmjopen-2015-010183).

DKK and HJS contributed equally as first authors.

Received 6 October 2015 Revised 18 April 2016 Accepted 11 May 2016

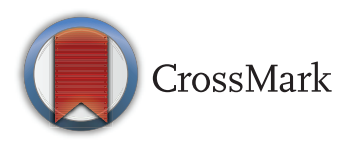

${ }^{1}$ College of Pharmacy and Research Institute of Pharmaceutical Sciences, Kyungpook National University, Daegu, Republic of South Korea

${ }^{2}$ Daegu Gyeongbuk Medical Innovation Foundation, Daegu, Republic of South Korea

${ }^{3}$ School of Pharmacy, Sungkyunkwan University, Suwon, Republic of South Korea

Correspondence to Professor Jin-Won Kwon; jwkwon@knu.ac.kr

\section{ABSTRACT}

Objectives: To examine the hypothesis that the relationship between obesity and the risk of suicidal behaviour would differ according to sex and age.

Setting: Data from the 2007-2012 Korean National Health and Nutrition Examination Survey (KNHANES) were used.

Participants: 36211 adults with body mass index (BMI) data were included and the mean age was 49.6 years.

Independent variable: BMI.

Primary and secondary outcome measures: Suicide ideation and attempts.

Design and analysis: A cross-sectional study was performed. Multiple logistic regressions after controlling for socioeconomic variables and concomitant diseases were applied to see the relationship between obesity level and suicidal ideation or attempt.

Results: Women with severe obesity had the highest prevalence of suicide attempts and ideation, whereas among males, underweight men had the highest prevalence. After adjustment, obese men had a lower $\mathrm{OR}$ for suicide ideation $(\mathrm{OR}=0.87,95 \% \mathrm{Cl} 0.76$ to 1.00). Among women, the ORs of severely obese and underweight women were 1.27 (95\% $\mathrm{Cl} 1.06$ to 1.52$)$ and $1.24(95 \% \mathrm{Cl} 1.06$ to 1.45$)$, respectively. When grouped by age category, the ORs for suicide ideation in severely obese women aged 18 to $<30$ years or attempts in severely obese women aged 30 to $<50$ years were $2.30(95 \% \mathrm{Cl} 1.36$ to 3.89$)$ and 3.07 (95\% Cl 1.50 to 6.31 ), respectively. However, overweight and obese women aged more than 50 years exhibited significantly less ORs of suicide ideation, when compared with counterparts of normal weight. Conclusions: The association between obesity and suicidal behaviour exhibited a different pattern by sex and age in South Korea. In particular, severely obese young women had a substantial risk of suicidal behaviour. Our study results highlighted the importance of obesity management in the prevention of suicide among young women, and may be helpful for the drafting of the health agenda in Asian countries with an obesity prevalence and culture similar to those in Korea.

\section{Strengths and limitations of this study}

- This study used a nationwide populationrepresentative 5-year combined survey data of Korean adults, and the large population sample size could represent the general population of adults in South Korea.

- Subgroup analysis by age and sex provide a clear understanding for the dynamic pattern between obesity level and suicidal behaviour including ideation and attempt.

- Reports of the respondents were a subjective recollection of thought and act of the previous year, potentially influenced by perception and recall bias.

- Owing to the lack of data, our study could not adjust the comorbid psychiatric disorders.

\section{INTRODUCTION}

Suicide is one of the major problems of public health throughout the world. Over the past 45 years, the suicide rate has increased by $60 \%$ and worldwide, 800000 people commit suicide every year. In particular, suicide is the second leading cause of death among young people aged between 15 and 29 years. ${ }^{1}$ In Korea, deaths from suicide soared after the economic crisis in $1997^{2}$ and, according to a report by the Ministry of Health and Welfare, in 2013, the suicide rate was 28.5 per 100000 people, the highest among all 33 Organization for Economic Co-operation and Development (OECD) member nations at the time. ${ }^{3}$

There are several well-established risk factors for suicide, including economic adversities, the family environment, the occurrence of a major life stressor (eg, unemployment) and substance abuse. ${ }^{4-6}$ Medical conditions have also been identified as risk factors. Among these, psychiatric disorders such as depression, anxiety, personality disorders and eating disorders are known to increase the risk of 
suicide. $^{7} 8$ In addition, patients with chronic illness, including cancer, osteoarthritis, rheumatoid arthritis, asthma and myocardial infarction are known to have a greater risk of suicide, as compared with healthy, nonclinical populations. $^{9-14}$

In the past several decades, the prevalence of obesity and suicide increased simultaneously, and several pioneering researchers have tried to elucidate as to whether the increases in body weight and suicide are independently linked or not. Notably, obesity-related comorbidities, such as dyslipidaemia, myocardial infarction, depression, anxiety, eating disorders and osteoarthritis, are also wellestablished risk factors for suicide, which further complicates the clarification of the current issue. ${ }^{15}$

In some reports, the relationship between obesity and suicidal behaviour such as suicide ideation and attempts differed according to sex; ${ }^{16}{ }^{17}$ it has also been reported that obese adolescents and young people are more vulnerable to the risk of suicidal behaviour. ${ }^{18}$ The prevalence of obesity is relatively lower in Asia than in western countries; ${ }^{19}$ this may influence the association between obesity and the risk of suicidal behaviour. In this study, we conducted subgroup analyses by sex and age to give a detailed clarification of the relationship between obesity and the risk of suicidal behaviour (ie, suicide ideation and suicide attempts) in South Korea.

\section{METHODS}

\section{Study samples and data collection}

In this study, we used the Korea National Health and Nutrition Examination Survey (KNHANES), conducted from 2007 to 2012. The KNHANES, established by the Korea Centers for Disease Control and Prevention (KCDC), is a nationwide, cross-sectional, noninstitutionalised household-based survey, aimed at monitoring the overall health status of the general Korean population. For a representative Korean national population, a complex stratified multistage probability cluster sampling design was used to select the household units for this survey. The structure of this survey was slightly modified every 3 years. We used data from the fourth (2007-2009) and the fifth KNHANES (2010-2012). Using the weight variables on this database, the integration of the fourth and the fifth KNHANES was possible. The analysed data can be considered representative of the national population. The KNHANES consisted of personal interviews comprising a nutritional survey and various health-related questions, including individual health examinations, concomitant diseases and suicidal behaviour (ie, suicide ideation and suicide attempts). Suicide behaviour in this manuscript is the comprehensive word including both suicide ideation and attempts. The individual data for the research were available to the public through the KNHANES home page (https:// knhanes.cdc.go.kr). The study protocol including study design, interview questionnaire and informed consent got approved by the ethics committee in KCDC.

\section{Independent variables of main interest}

Obesity was defined by body mass index (BMI), according to Asian criteria, ${ }^{20} 21$ as follows: underweight $(<18.5)$, normal weight $(18.5$ to $<23)$, overweight $(23$ to $<25)$, obesity $(25$ to $<30)$ and severe obesity $(\geq 30)$. BMI $\left(\mathrm{kg} / \mathrm{m}^{2}\right)$ was calculated using the data obtained on weight $(\mathrm{kg})$ and height $(\mathrm{m})$ during health examinations. The participants' weight and height were measured by trainees at an investigation agency.

\section{Dependent variables}

Suicide ideation involves thoughts about or an unusual preoccupation with suicide. This was assessed by asking whether participants had experienced suicide ideation within the previous year or not. The specific question is 'Have you ever thought about committing suicide within the previous year?'. This question was coded as a dichotomous variable (yes/no).

A history of suicide attempts was assessed through one self-report item, namely, 'Have you attempted suicide within the previous year?'. This question was coded as a dichotomous variable (yes/no).

\section{Covariate variables}

\section{Concomitant diseases}

Concomitant diseases related to obesity were investigated through health examinations and individual answers to the questionnaires. Blood pressure and several laboratory tests (eg, triglycerides, high-density lipoprotein (HDL) cholesterol and fasting plasma glucose (FPG)) were performed. Hypertension, dyslipidaemia and diabetes were determined through abnormal health examination results or a physician's diagnosis, as shown in the questionnaires. The criteria for an abnormal health examination were: blood pressure for hypertension, indicated by a systolic pressure of $>140 \mathrm{~mm} \mathrm{Hg}$ or diastolic pressure of $>90 \mathrm{~mm} \mathrm{Hg},{ }^{22}$ diabetes glucose level $(\geq 126 \mathrm{mg} / \mathrm{dL}),{ }^{23}$ total cholesterol level $(\geq 240 \mathrm{mg} / \mathrm{dL})$, LDL-cholesterol level ( $\geq 160 \mathrm{mg} / \mathrm{dL}$ ), HDL-cholesterol level of $<40 \mathrm{mg} / \mathrm{dL}$ or a triglyceride level of $\geq 200 \mathrm{mg} / \mathrm{dL}$ for dyslipidaemia. ${ }^{22}$ If patients indicated on the questionnaires that they had been diagnosed with coronary heart disease (eg, angina pectoris (AP) and myocardial infarction (MI)), stroke, depression and osteoarthritis through physicals, they were defined as having those diseases.

\section{Sociodemographic variables}

Marital status, education level, household income and smoking status were considered to adjust socioeconomic status. The categories for marital status included single, married and other, which included divorced/widowed/ separated. Education-level categories included graduation from elementary school or lower, graduation from middle school, graduation from high school, and a Bachelor's degree or higher. Household income level was grouped into four quadrants. smoking status included none, current smoker and ex-smoker. 


\section{Analytical approach and statistics}

Patient characteristics, including age, sex, socioeconomic status and concomitant diseases were summarised descriptively by obesity level. Categorical data were summarised by frequency and continuous data by the mean and the SE. The number of patients with suicidal behaviour (ie, suicide ideation and suicide attempts) was summarised by obesity level. The relationship between obesity level and suicidal behaviour according to sex was determined through multiple logistic regressions, after controlling for socioeconomic variables and concomitant diseases. Multiple logistic regressions were performed in 34482 (suicidal ideation) and 34448 adults (suicidal attempt) excluding people who had missing data for each variable. To determine differences in the effect of obesity by age group, a subgroup analysis was also conducted. To convert the national estimates, the structure of the survey's sampling design and weights were reflected in the statistical analysis. This study complied with STROBE (Strengthening the Reporting of Observational Studies in Epidemiology) guidelines for cross-sectional studies. The statistical software programs used for this study are SAS V.9.3 (SAS Inc, Cary, North Carolina, USA) and STATA V.12 (Stata Corp, College Station, Texas, USA).

\section{RESULTS}

\section{Characteristics and univariate analyses}

A total of 36211 individuals with BMI data were selected among 38497 and the mean age was 49.6 years. The percentages of individuals who were underweight, of normal weight, overweight, obese and severely obese were $4.8 \%, 40.3 \%, 23.5 \%, 27.7 \%$ and $3.8 \%$, respectively. Patient characteristics, including demographic information, socioeconomic status and concomitant diseases, were summarised by obesity level (table 1 ). The presence of concomitant diseases was $26.0 \%$ for people of normal weight and $76.8 \%$ for people with severe obesity.

The results of suicide ideation for men and women showed a U-shaped curve by obesity level. However, there were slight gender differences. Among men, those who were underweight had the highest prevalence of suicide ideation, whereas among women, those who were severely obese had the highest prevalence. With regard to suicide attempts, men had lower prevalence as their obesity levels increased. However, the prevalence of suicide attempts was highest in women with severe obesity (figure 1).

\section{Multiple logistic regression analyses}

After controlling for other sociodemographic factors and concomitant diseases, obese men had a low OR for suicide ideation ( $\mathrm{OR}=0.87,95 \%$ CI 0.76 to 1.00$)$. Among women, the ORs of severely obese or underweight women were 1.27 (95\% CI 1.06 to 1.52$)$ and 1.24 (95\% CI 1.06 to 1.45$)$, respectively. However, the severity of obesity did not have a significant effect on suicide attempts among men and women (table 2).

When grouped by age category, severely obese women aged $\leq 50$ years mostly showed significantly higher ORs for suicide ideation or attempts, as compared with normal weight women in the same age range. For women aged 18 to $<30$ years, the ORs for suicide ideation and attempts among severely obese women were 2.30 (95\% CI 1.36 to 3.89 ) and 1.22 (95\% CI 0.43 to $3.48)$, respectively. The ORs were 1.62 (95\% CI 1.21 to 2.16 ) and 3.07 (95\% CI 1.50 to 6.31 ), respectively, among women aged 30 to $<50$ years. Overweight and obese women aged more than 50 years exhibited significantly lower ORs of suicide ideation, at 0.87 (95\% CI 0.76 to 0.99 ) and 0.85 (95\% CI 0.75 to 0.96 ), respectively, when compared with counterparts of normal weight (table 3). Despite statistical insignificance, women in the older age group, who had a high BMI, consistently showed lower ORs of suicide attempts when compared with their counterparts of normal BMI.

\section{DISCUSSION}

In the current study, we found sex differences in the association between BMI and suicidal behaviour. In our study, the prevalence of suicide ideation and attempts by BMI differed substantially between men and women. Among men, as the level of BMI increased from underweight to severe obesity, the prevalence of suicide attempts decreased in a linear pattern. However, among women, we found a high prevalence of suicide attempts in the severely obese group. The results also showed sex differences in suicide ideation. Men in the underweight group had the highest prevalence of suicide ideation; among women, the highest prevalence was found among those in the severely obese group.

After controlling for other demographic and clinical information, severely obese women had a significantly higher OR for suicide ideation and tended to have a higher OR of suicide attempts, although statistical significance was not obtained.

Previous reports did not show consistent results regarding the association between obesity and the risk of suicidal behaviour. Whereas some articles indicated obesity as having a protective effect on suicide risk, ${ }^{16} 24-33$ others reported that it had a negative impact on suicide risk. ${ }^{34-40}$ Therefore, whether the worldwide prevalence of obesity and suicide is independent of one another, is positively or inversely linked, or not, remains to be established. ${ }^{15}$ 41-43

Regarding completed suicide, there is a seemingly inverse relationship between BMI and death from suicide. In other words, an increase in BMI had protective effects on completed suicide in previous studies. An inverse association between BMI and suicide has also been consistently observed in different countries among adult samples of Caucasian males; ${ }^{24} 25{ }^{31}$ recent studies have also extended the findings on this inverse 
Table 1 General characteristics of the study population

\begin{tabular}{|c|c|c|c|c|c|c|}
\hline $\begin{array}{l}\text { Variables } \\
\mathrm{N}(\%)\end{array}$ & Total & $\begin{array}{l}\text { Underweight } \\
(<18.5)\end{array}$ & $\begin{array}{l}\text { Normal weight } \\
(18.5 \text { to }<23)\end{array}$ & $\begin{array}{l}\text { Overweight } \\
(23 \text { to }<25)\end{array}$ & $\begin{array}{l}\text { Obese } \\
(25 \text { to }<30)\end{array}$ & $\begin{array}{l}\text { Severely } \\
\text { obese }(\geq 30)\end{array}$ \\
\hline Total & 36211 (100.0\%) & $1729(4.8 \%)$ & $14583(40.3 \%)$ & 8508 (23.5\%) & $10030(27.7 \%)$ & $1361(3.8 \%)$ \\
\hline \multicolumn{7}{|c|}{ ( } \\
\hline Men & $15428(42.6 \%)$ & $537(31.1 \%)$ & 5546 (38.0\%) & 4036 (47.4\%) & $4815(48.0 \%)$ & $494(36.3 \%)$ \\
\hline Women & $20783(57.4 \%)$ & $1192(68.9 \%)$ & 9037 (62.0\%) & 4472 (52.6\%) & $5215(52.0 \%)$ & 867 (63.7\%) \\
\hline \multicolumn{7}{|l|}{ Age (years) } \\
\hline Mean (SE) & $49.6(0.2)$ & $43.1(0.6)$ & $47.6(0.2)$ & $51.7(0.2)$ & $52.2(0.2)$ & $47.4(0.5)$ \\
\hline $18-29$ & 4862 (13.4\%) & 600 (34.7\%) & 2512 (17.2\%) & $769(9.0 \%)$ & $771(7.7 \%)$ & $210(15.4 \%)$ \\
\hline 30-39 & $6832(18.9 \%)$ & $392(22.7 \%)$ & 3184 (21.8\%) & $1378(16.2 \%)$ & $1582(15.8 \%)$ & $296(21.7 \%)$ \\
\hline $40-49$ & 6677 (18.4\%) & $174(10.1 \%)$ & 2599 (17.8\%) & 1667 (19.6\%) & 1965 (19.6\%) & $272(20.0 \%)$ \\
\hline $50-59$ & 6419 (17.7\%) & $108(6.2 \%)$ & 2153 (14.8\%) & 1785 (21.5\%) & 2155 (21.5\%) & $218(16.0 \%)$ \\
\hline$\geq 60$ & 11421 (31.5\%) & $455(26.3 \%)$ & 4135 (28.4\%) & 2909 (34.2\%) & 3557 (35.5\%) & 365 (26.8\%) \\
\hline \multicolumn{7}{|l|}{ Smoking status } \\
\hline None & $10762(30.3 \%)$ & $482(28.9 \%)$ & 4046 (28.4\%) & 2675 (32.1\%) & 3137 (31.8\%) & $422(31.5 \%)$ \\
\hline Current smoker & $3620(10.2 \%)$ & $114(6.8 \%)$ & $1265(8.9 \%)$ & 962 (11.5\%) & $1181(12.0 \%)$ & $98(7.3 \%)$ \\
\hline Ex-smoker & 21104 (59.5\%) & $1073(64.3 \%)$ & 8956 (62.8\%) & 4704 (56.4\%) & 5552 (56.3\%) & $819(61.2 \%)$ \\
\hline \multicolumn{7}{|l|}{ Marital status } \\
\hline Married & $25810(71.7 \%)$ & $940(54.7 \%)$ & 9989 (68.5\%) & $6422(76.0 \%)$ & $7558(75.8 \%)$ & $901(66.7 \%)$ \\
\hline Single & $5273(14.6 \%)$ & $585(34.1 \%)$ & 2693 (18.6\%) & $883(10.4 \%)$ & $878(8.8 \%)$ & $234(17.3 \%)$ \\
\hline $\begin{array}{l}\text { Divorced/widowed/ } \\
\text { separated }\end{array}$ & $4913(13.6 \%)$ & $193(11.2 \%)$ & $1817(12.5 \%)$ & $1150(13.6 \%)$ & $1537(15.4 \%)$ & $216(16.0 \%)$ \\
\hline \multicolumn{7}{|l|}{ Education } \\
\hline $\begin{array}{l}\text { Elementary school } \\
\text { degree or less }\end{array}$ & $9594(27.1 \%)$ & $368(22.0 \%)$ & $3337(23.4 \%)$ & $2375(28.6 \%)$ & $3117(31.7 \%)$ & $397(29.7 \%)$ \\
\hline $\begin{array}{l}\text { Middle school } \\
\text { degree }\end{array}$ & 4085 (11.5\%) & $124(7.4 \%)$ & $1444(10.1 \%)$ & 1075 (12.9\%) & $1289(13.1 \%)$ & $153(11.4 \%)$ \\
\hline High school degree & 12005 (33.9\%) & $580(34.6 \%)$ & $5181(36.4 \%)$ & $2711(32.7 \%)$ & 3047 (31.0\%) & $486(36.3 \%)$ \\
\hline $\begin{array}{l}\text { Bachelor's degree } \\
\text { or more }\end{array}$ & $9687(27.4 \%)$ & $602(36.0 \%)$ & $4272(30.0 \%)$ & 2142 (25.8\%) & 2369 (24.1\%) & $302(22.6 \%)$ \\
\hline \multicolumn{7}{|l|}{ House income } \\
\hline Low income & $7297(20.6 \%)$ & $361(21.4 \%)$ & 2860 (20.0\%) & 1655 (19.9\%) & $2141(21.7 \%)$ & $280(21.0 \%)$ \\
\hline Mid-lower income & 8999 (25.4\%) & $399(23.6 \%)$ & 3514 (24.6\%) & $2119(25.5 \%)$ & $2546(25.9 \%)$ & $421(31.6 \%)$ \\
\hline Mid-upper income & 9534 (26.9\%) & $437(25.9 \%)$ & 3965 (27.8\%) & 2172 (26.1\%) & 2600 (26.4\%) & $360(27.0 \%)$ \\
\hline High income & $9634(27.2 \%)$ & $492(29.1 \%)$ & 3934 (27.6\%) & 2377 (28.6\%) & $2558(26.0 \%)$ & $273(20.5 \%)$ \\
\hline \multicolumn{7}{|l|}{ Disease } \\
\hline None & 16217 (44.8\%) & $1280(74.0 \%)$ & 8245 (57.8\%) & 3402 (40.0\%) & 2794 (27.9\%) & $316(23.2 \%)$ \\
\hline Any of the following & 19994 (55.2\%) & 449 (26.0\%) & 6158 (42.2\%) & $5106(60.0 \%)$ & $7236(72.1 \%)$ & $1045(76.8 \%)$ \\
\hline Hypertension & $11196(30.9 \%)$ & $227(13.1 \%)$ & 3057 (21.0\%) & 2792 (32.8\%) & $4420(44.1 \%)$ & $700(51.4 \%)$ \\
\hline Diabetes & 3551 (9.8\%) & $60(3.5 \%)$ & $966(6.6 \%)$ & $855(10.0 \%)$ & $1414(14.1 \%)$ & $256(18.8 \%)$ \\
\hline Dyslipidaemia & $11755(32.5 \%)$ & $182(10.5 \%)$ & $3221(22.1 \%)$ & $3086(36.3 \%)$ & $4629(46.2 \%)$ & $637(46.8 \%)$ \\
\hline $\begin{array}{l}\text { Coronary heart } \\
\text { disease }\end{array}$ & $863(2.4 \%)$ & $16(0.9 \%)$ & $239(1.6 \%)$ & $241(2.8 \%)$ & $325(3.2 \%)$ & $42(3.1 \%)$ \\
\hline Stroke & $718(2.0 \%)$ & $23(1.3 \%)$ & 235 (1.6\%) & $183(2.2 \%)$ & $248(2.5 \%)$ & $29(2.1 \%)$ \\
\hline Osteoarthritis & $4157(11.5 \%)$ & $62(3.6)$ & $1148(7.9 \%)$ & $1040(12.2 \%)$ & $1654(16.5 \%)$ & $253(18.6 \%)$ \\
\hline Depression & $1375(3.8 \%)$ & $46(2.7 \%)$ & $529(3.6 \%)$ & $320(3.8 \%)$ & $419(4.2 \%)$ & $61(4.5 \%)$ \\
\hline
\end{tabular}

relationship to the whole population. ${ }^{26-29}$ Several studies have tried to elucidate on putative mechanisms for the association, and have explained that the relationship may partly be due to differences in suicide methods, according to BMI. ${ }^{29} 3032$

The association between BMI and suicidal behaviour, especially suicide ideation and attempts, is quite inconsistent, and fewer studies have been conducted compared with completed suicide. ${ }^{15}$ Regarding suicide attempts, sex differences had a substantial influence on the relationship between BMI and suicide attempts. The majority of studies have reported that men with a high BMI had a low OR of suicide attempts. In the same context, underweight men exhibited a higher OR of suicide attempts than did their counterparts of average weight. On the other hand, women with a high BMI have been found to have a high tendency of suicide attempts. ${ }^{16} \quad 17 \quad 31 \quad 33$ However, few studies have reported an association between extreme obesity and a higher number of suicide attempts among both men and women. ${ }^{34} 38$ In our study, similar sex differences were observed in the Korean population, despite the lack of statistical significance. 


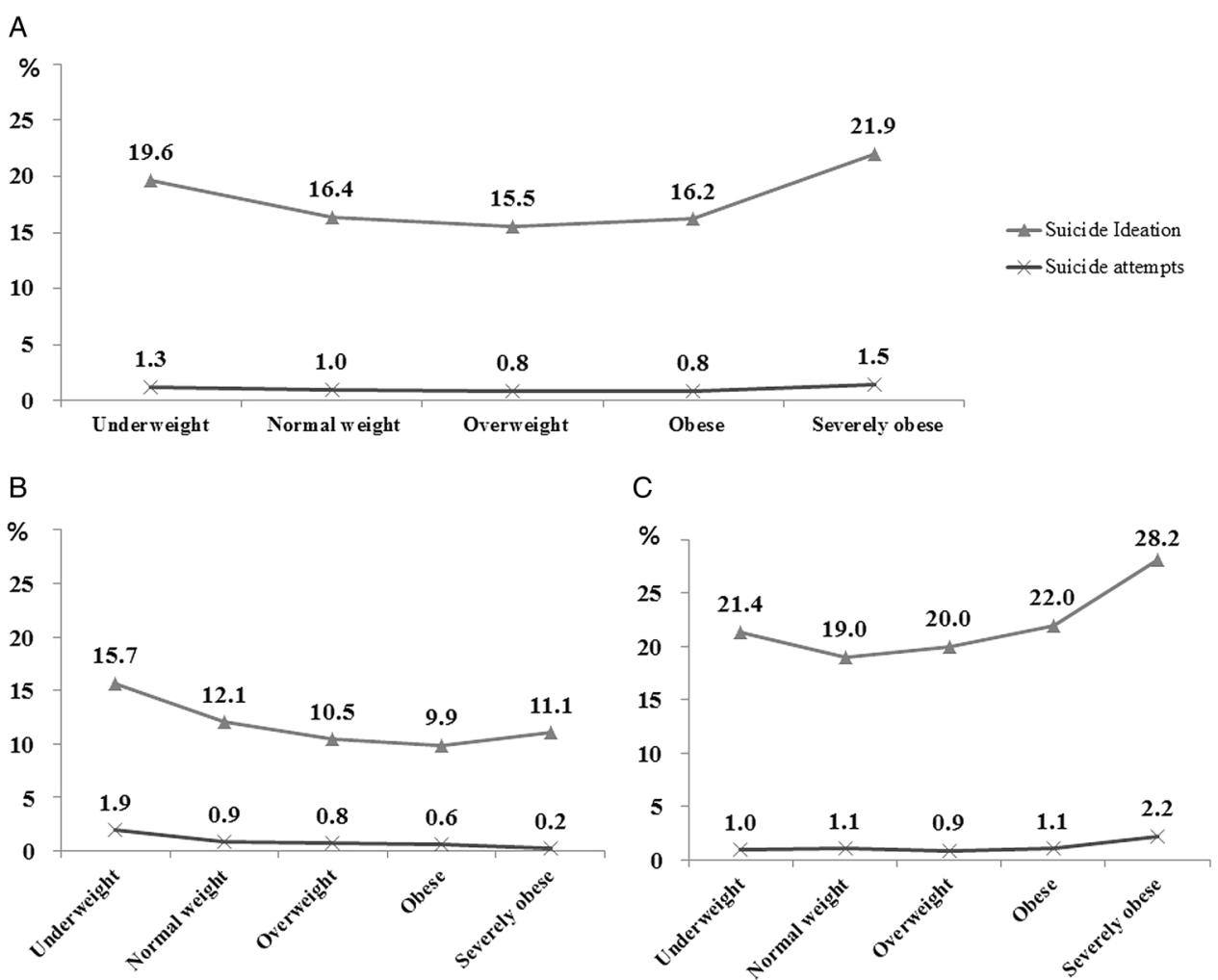

Figure 1 Prevalence rate of suicide ideation and attempts by obesity level (A) overall, (B) among men and (C) among women.

Few studies have been conducted on suicide ideation among obese people. ${ }^{15} 42$ Among women, most studies have revealed a positive relationship between BMI and suicide ideation. ${ }^{17} \quad 36 \quad 37$ However, the association between the two was found to be inconsistent among men. In 2000, Carpenter and colleagues reported the protective effect of BMI on suicide ideation, indicating high suicide ideation among underweight men $(\mathrm{OR}=1.81 ; 95 \%$ CI 1.71 to 1.89$)$, as compared with men of average weight. However, in 2009, Mather and colleagues revealed a high OR of suicide ideation among obese men $(\mathrm{OR}=2.00 ; 95 \%$ CI 1.33 to 3.03$)$, as compared with non-obese men. In addition, most studies oriented towards adolescents have reported a high tendency of suicide ideation among obese boys. ${ }^{37} 39$ In our study, obese men had a lower OR of experiencing suicide ideation and underweight and severely obese women had higher ORs than did counterparts of normal weight.

For an in-depth analysis of the association between obesity and suicidal behaviour among women, we conducted subgroup analyses by age groups (ie, the younger age group $(<30)$, the middle age group $(30-49.9)$ and the older age group $(50 \geq))$. Interestingly, the association between obesity and suicide ideation or attempts exhibited different patterns according to age group. Among severely obese women, there was a seemingly inverse relationship between age and suicidal behaviour. With a decrease in age, the OR of suicide ideation and attempts increased significantly. Consequently, severely obese women had the highest ORs of suicide ideation $(\mathrm{OR}=2.30 ; 95 \%$ CI 1.36 to 3.89$)$ in the younger age group and suicide attempts $(\mathrm{OR}=3.07 ; 95 \%$ CI 1.50 to 6.31 ) in the middle age group.

Considering the social stigma towards obese individuals in Korean society, it seems that obese women in the younger age group may have had more social stressors, including social relationships. Some studies mentioned the prevailing stereotypes against obese people, that they are less hard working, productive, successful, intelligent, attractive and self-disciplined than are nonobese people. ${ }^{44}$ The negative social perceptions about obesity may lead to the social discrimination of obese people, especially that of young people seeking employment and partners. Actually, some Korean studies have found misconceptions regarding body image to be more common among younger people. ${ }^{45} 46$ Higher suicide ideation and attempts among younger people in our study may indicate the severity of social discrimination towards obese women. One study mentioned that the social stigmatisation of obese people leads to health disparities and relatively poor health among this group, and has a negative impact on the effectiveness of interventions for obesity. ${ }^{44}$ Thus, efforts in public health, which are aimed at decreasing the social stigmatisation of obesity, may be required to facilitate a decrease in incidences of suicide and effective management of obesity.

Furthermore, the trend regarding the inverse relationship between obesity and OR of suicidal behaviour in 
Table 2 Association between obesity and suicidal ideation or suicide attempt by gender

\begin{tabular}{|c|c|c|c|c|c|c|c|c|}
\hline \multirow[b]{3}{*}{ Variables } & \multicolumn{4}{|c|}{ Suicidal ideation } & \multicolumn{4}{|c|}{ Suicidal attempt } \\
\hline & \multicolumn{2}{|c|}{ Women } & \multicolumn{2}{|l|}{ Men } & \multicolumn{2}{|c|}{ Women } & \multicolumn{2}{|l|}{ Men } \\
\hline & OR & $95 \% \mathrm{Cl}$ & OR & $95 \% \mathrm{Cl}$ & OR & $95 \% \mathrm{Cl}$ & OR & $95 \% \mathrm{Cl}$ \\
\hline \multicolumn{9}{|l|}{$\mathrm{BMI}$} \\
\hline Underweight & 1.24 & 1.06 to 1.45 & 1.21 & 0.93 to 1.56 & 0.99 & 0.49 to 2.01 & 1.70 & 0.77 to 3.74 \\
\hline Normal weight & 1 & & 1 & & 1 & & 1 & \\
\hline Overweight & 0.95 & 0.86 to 1.05 & 0.89 & 0.78 to 1.03 & 0.76 & 0.50 to 1.16 & 0.97 & 0.61 to 1.55 \\
\hline Obese & 0.94 & 0.85 to 1.04 & 0.87 & 0.76 to 1.00 & 0.81 & 0.56 to 1.17 & 0.69 & 0.43 to 1.11 \\
\hline Severely obese & 1.27 & 1.06 to 0.52 & 1.11 & 0.80 to 1.53 & 1.53 & 0.91 to 2.56 & 0.30 & 0.04 to 2.16 \\
\hline \multicolumn{9}{|l|}{ Age (years) } \\
\hline $18-29$ & 1 & & 1 & & 1 & & 1 & \\
\hline $30-39$ & 0.89 & 0.74 to 1.07 & 1.61 & 1.22 to 2.12 & 0.77 & 0.36 to 1.62 & 1.79 & 0.55 to 5.88 \\
\hline $40-49$ & 0.92 & 0.76 to 1.11 & 1.93 & 1.42 to 2.61 & 1.19 & 0.56 to 2.53 & 2.42 & 0.81 to 7.22 \\
\hline $50-59$ & 0.71 & 0.57 to 0.89 & 2.01 & 1.47 to 2.77 & 0.38 & 0.17 to 0.86 & 1.43 & 0.44 to 4.64 \\
\hline$\geq 60$ & 0.77 & 0.61 to 0.96 & 1.76 & 0.26 to 2.46 & 0.22 & 0.09 to 0.54 & 0.91 & 0.26 to 3.12 \\
\hline \multicolumn{9}{|l|}{ Smoking status } \\
\hline None & 1 & & 1 & & 1 & & 1 & \\
\hline Current smoker & 1.98 & 1.76 to 2.22 & 0.75 & 0.65 to 0.86 & 3.36 & 2.44 to 4.63 & 0.84 & 0.49 to 1.44 \\
\hline Ex-smoker & 1.37 & 1.11 to 1.69 & 0.69 & 0.59 to 0.81 & 1.45 & 0.71 to 2.95 & 1.29 & 0.77 to 2.17 \\
\hline \multicolumn{9}{|l|}{ Marital status } \\
\hline Single & 1 & & 1 & & 1 & & 1 & \\
\hline Married & 0.75 & 0.62 to 0.90 & 0.51 & 0.40 to 0.64 & 0.58 & 0.28 to 1.17 & 0.46 & 0.21 to 1.01 \\
\hline Divorced/widowed/separated & 0.92 & 0.75 to 1.13 & 0.95 & 0.72 to 1.27 & 0.78 & 0.36 to 1.67 & 1.11 & 0.46 to 2.68 \\
\hline \multicolumn{9}{|l|}{ Education } \\
\hline Elementary school degree or less & 1 & & 1 & & 1 & & 1 & \\
\hline Middle school degree & 0.65 & 0.57 to 0.75 & 0.67 & 0.56 to 0.80 & 0.48 & 0.29 to 0.79 & 0.89 & 0.53 to 1.48 \\
\hline High school degree & 0.54 & 0.47 to 0.61 & 0.56 & 0.48 to 0.66 & 0.30 & 0.18 to 0.49 & 0.31 & 0.18 to 0.54 \\
\hline Bachelor's degree or more & 0.45 & 0.38 to 0.53 & 0.49 & 0.40 to 0.59 & 0.18 & 0.10 to 0.34 & 0.12 & 0.05 to 0.33 \\
\hline \multicolumn{9}{|l|}{ House income } \\
\hline Low income & 1 & & 1 & & 1 & & 1 & \\
\hline Mid-lower income & 0.79 & 0.72 to 0.88 & 0.78 & 0.68 to 0.90 & 0.61 & 0.42 to 0.90 & 0.51 & 0.30 to 0.87 \\
\hline Mid-upper income & 0.72 & 0.64 to 0.81 & 0.58 & 0.49 to 0.69 & 0.66 & 0.44 to 1.00 & 0.50 & 0.28 to 0.88 \\
\hline High income & 0.57 & 0.50 to 0.64 & 0.53 & 0.44 to 0.64 & 0.25 & 0.14 to 0.45 & 0.52 & 0.27 to 0.97 \\
\hline \multicolumn{9}{|l|}{ Disease } \\
\hline None & 1 & & 1 & & 1 & & 1 & \\
\hline Hypertension & 0.96 & 0.87 to 1.05 & 0.97 & 0.86 to 1.09 & 0.72 & 0.51 to 1.03 & 1.22 & 0.79 to 1.89 \\
\hline Diabetes & 1.05 & 0.93 to 1.19 & 1.13 & 0.96 to 1.33 & 1.20 & 0.78 to 1.84 & 1.01 & 0.57 to 1.80 \\
\hline Dyslipidaemia & 1.08 & 0.99 to 1.17 & 1.09 & 0.97 to 1.23 & 1.00 & 0.71 to 1.41 & 1.04 & 0.66 to 1.61 \\
\hline Coronary heart disease & 1.53 & 1.23 to 1.90 & 1.59 & 1.22 to 2.08 & 2.21 & 1.13 to 4.35 & 2.37 & 1.08 to 5.19 \\
\hline Stroke & 1.64 & 1.31 to 2.05 & 1.70 & 1.29 to 2.24 & 1.04 & 0.43 to 2.52 & 1.58 & 0.72 to 3.51 \\
\hline Osteoarthritis & 1.30 & 1.19 to 1.43 & 1.52 & 1.25 to 1.85 & 2.33 & 1.65 to 3.30 & 3.36 & 1.99 to 5.69 \\
\hline Depression & 3.16 & 2.77 to 3.61 & 5.35 & 4.01 to 7.14 & 7.72 & 5.59 to 10.66 & 8.18 & 4.70 to 14.24 \\
\hline
\end{tabular}

BMI, body mass index.

the older age group remains to be established. It might be partly explained by Korean society's higher tolerance for overweight or obesity among aged women. It has been reported that white women consistently report higher body dissatisfaction than do black women, regardless of the severity of obesity; this trend is explained by differences in social acceptance. ${ }^{47}{ }^{48}$ In a simple conjecture, low social stress regarding being overweight or obese among aged Korean women might potentiate the protective physiological features of obese people, such as increased serum levels of free fatty acid and its link to central serotonin. ${ }^{49}{ }^{50}$ In biological psychiatry, the most replicated finding is a low and experimentally lowered central serotonin and its linkage with increased suicide, aggression and reduced harm avoidance. In obese people, the insulin resistance syndrome is associated with increased blood level of free fatty acids, which compete with tryptophan for binding to serum albumin. As a result, increased unbound tryptophan in the blood could easily penetrate the blood brain barrier, which is the ratelimiting step of serotonin synthesis, and result in increased central synthesis of serotonin. Increased central serotonin synthesis might be related to the protective effects on the risk of suicidal behaviour. Similarly, some researchers have reported that postmenopausal women with a higher BMI obtained lower scores on depressive symptoms. ${ }^{51}$

In our study, suicidal behaviours were associated with sociodemographic variables such as the family 
Table 3 Association between obesity and suicidal ideation or suicide attempt by age group in women

\begin{tabular}{|c|c|c|c|c|}
\hline \multirow[b]{2}{*}{ Age group } & \multicolumn{2}{|c|}{ Suicidal ideation } & \multicolumn{2}{|c|}{ Suicidal attempt } \\
\hline & $\overline{\text { OR }}$ & $95 \% \mathrm{Cl}$ & $\overline{\text { OR }}$ & $95 \% \mathrm{Cl}$ \\
\hline \multicolumn{5}{|l|}{$<30$ years old } \\
\hline Underweight & 0.94 & 0.70 to 1.24 & 1.00 & 0.28 to 3.65 \\
\hline Normal weight & 1 & & 1 & \\
\hline Overweight & 1.16 & 0.84 to 1.59 & 1.90 & 0.64 to 5.64 \\
\hline Obesity & 1.04 & 0.75 to 1.46 & 0.62 & 0.10 to 3.79 \\
\hline Severe obesity & 2.30 & 1.36 to 3.89 & 1.22 & 0.43 to 3.48 \\
\hline \multicolumn{5}{|l|}{$30-49$ years old } \\
\hline Underweight & 1.69 & 1.30 to 2.20 & 0.31 & 0.04 to 2.35 \\
\hline Normal weight & 1 & & 1 & \\
\hline Overweight & 1.01 & 0.85 & 0.58 & .24 \\
\hline Obesity & 1.09 & 0.90 to 1.31 & 0.82 & 0.40 to 1.67 \\
\hline Severe obesity & 1.62 & 1.21 to 2.16 & 3.07 & 1.50 to 6.31 \\
\hline \multicolumn{5}{|l|}{$\geq 50$ years old } \\
\hline Underweight & 1.30 & 0.96 to 1.76 & 1.98 & 0.72 to 5.44 \\
\hline Normal weight & 1 & & 1 & \\
\hline Overweight & 0.87 & 0.76 to 0.99 & 0.69 & 0.40 to 1.20 \\
\hline Obesity & 0.85 & 0.75 to 0.96 & 0.78 & 0.49 to 1.22 \\
\hline Severe obesity & 0.91 & 0.72 to 1.17 & 0.57 & 0.20 to 1.64 \\
\hline
\end{tabular}

Adjusted for age, smoking status, education, marital status, education, house income and concomitant disease (hypertension, diabetes, dyslipidaemia, coronary heart disease, stroke, osteoarthritis and depression).

environment (eg, marital status), educational level and household income level, as well as medical variables such as comorbidities. Among these, there was a discernible inverse link between OR of suicidal behaviour, educational and household income levels. Our results were consistent with those of previous Korean studies and those conducted in western countries. ${ }^{24} 52$ Regarding smoking status, current smokers in women showed statistically significant associations with suicide behaviours similar to that of a previous study. ${ }^{5}$ However, smoking in men showed quite a different pattern. Current smokers in men exhibited reduced OR of suicide ideation with statistical significance even though the statistical association was not existed for suicide attempts. Further research on the sex difference in relationship between smoking and suicide behaviour would be required.

Some medical comorbidities were also related to an elevated OR of suicidal behaviour in Korea. Coronary heart disease (MI, AP) and osteoarthritis were linked to a high OR of suicidal behaviour, whereas dyslipidaemia and stroke were associated with an elevated OR of suicide ideation, but not suicide attempts. However, hypertension and diabetes were not associated with suicidal behaviour. Generally, psychological disorders and multiple illnesses reportedly have a strong association with the risk of suicide. $^{7}{ }^{8}{ }^{14}$ Specifically, chronic pain with high recurrence and ambiguous diagnoses has also been associated with an elevated risk of suicide..$^{91-13}$ Similarly, in our study, regardless of sex, people with depression exhibited the highest ORs of suicide ideation and attempts. In the same context, people with osteoarthritis showed elevated ORs of suicide attempts in men and women.
Our study has obvious limitations. First, the nature of cross-sectional design used in our study entails a measurement bias because BMI was measured at the time of recruitment while suicide behaviour was a retrospective recollection of thought and acts within the previous year. Therefore, we could not test for causal inferences regarding the development of suicidal behaviours and obesity over time. Second, we used suicidal behaviours (ie, suicide ideation and suicide attempts) only in the analysis. Therefore, the association between obesity and completed suicide could not be elucidated. Especially, due to the limitation of general population-based survey, the definition of suicide attempts was presented with a general terms to the respondents, therefore suicide attempts in our study inevitably include the cases of selfinjury related with certain psychiatric disorders such as borderline personality disorder. Third, we could not describe and adjust the comorbid psychiatric disorders such as anxiety, eating disorders and borderline personality disorder due to lack of data. Fourth, we conducted the subgroup analysis by sex and age level. It might weaken the statistical significance due to the small sample size. Finally, the data in our study were collected through face-to-face interviews; therefore, interviewer bias could not be excluded.

Although our study has several limitations, it made several meaningful findings. First, we found that the association between obesity and suicidal behaviour among Korean women varies according to age range in a given population. There are few studies indicating this association according to age range, especially in Asian countries. Second, the different results obtained among women according to age range, particularly the low risk of suicidal behaviour among severely obese women in the older age group, highlighted the importance of considering the age range when investigating the correlation between obesity and suicidal behaviour among women. A subgroup analysis of age groups may be required.

Despite previous studies, whether the obesity and suicide are independently associated or not is still unclear. Meanwhile, obesity and suicide have become a major issue on public health throughout the world. From a practical point of view, it seems that further researches on a discovery of specific conditions, which could amplify the risk of suicide in obese people, are necessary in different cultures.

\section{CONCLUSIONS}

The association between obesity and suicidal behaviour exhibited a different pattern by sex and age in South Korea. In particular, severely obese women aged $<50$ years were at a high tendency of experiencing suicidal behaviour, such as suicide ideation and attempts. Our study results highlighted the importance of prioritising obesity management among young women within public health in Korea. Furthermore, our study results may prove helpful to other Asian countries with a 
similar culture in relation to gender and relatively low prevalence of obesity, such as that in South Korea, in setting up the health agenda.

Contributors D-KK, HJS, J-WK designed the study, researched the data, performed the statistical analyses and wrote the manuscript. E-KL and J-WK revised it critically for important intellectual content. All authors read and approved the final manuscript.

Funding This research received no specific grant from any funding agency in the public, commercial or not-for-profit sectors.

Competing interests None declared.

Patient consent Obtained.

Ethics approval The study protocol including study design, interview questionnaire and informed consent got approved by the ethics committee in KCDC.

Provenance and peer review Not commissioned; externally peer reviewed.

Data sharing statement No additional data are available.

Open Access This is an Open Access article distributed in accordance with the Creative Commons Attribution Non Commercial (CC BY-NC 4.0) license, which permits others to distribute, remix, adapt, build upon this work noncommercially, and license their derivative works on different terms, provided the original work is properly cited and the use is non-commercial. See: http:// creativecommons.org/licenses/by-nc/4.0/

\section{REFERENCES}

1. World Health Organization. Suicide. Fact Sheet \#398. Geneva World Health Organization, 2014. http://www.who.int/mediacentre/ factsheets/fs398/en/

2. Kwon JW, Chun H, Cho SI. A closer look at the increase in suicide rates in South Korea from 1986-2005. BMC Public Health 2009;9:72.

3. Korean ministry of Health and Welfare. Statistics of cause-specific death in South Korea. Korean Ministry of Health and Welfare, 2015. http://m.mw.go.kr/mobile/noticeView.jsp?MENU_ID=0403\&cont_ seq $=299571$ \&page $=4$

4. Inder KJ, Handley TE, Johnston A, et al. Determinants of suicidal ideation and suicide attempts: parallel cross-sectional analyses examining geographical location. BMC Psychiatry 2014;14:208.

5. Schneider B, Lukaschek K, Baumert J, et al. Living alone, obesity, and smoking increase risk for suicide independently of depressive mood findings from the population-based MONICA/KORA Augsburg cohort study. J Affect Disord 2014;152-154:416-21.

6. World Health Organization. Preventing suicide: a global imperative. Geneva: World Health Organization, 2014.

7. Juurlink DN, Herrmann N, Szalai JP, et al. Medical illness and the risk of suicide in the elderly. Arch Intern Med 2004;164:1179-84.

8. Petry NM, Barry D, Pietrzak $\mathrm{RH}$, et al. Overweight and obesity are associated with psychiatric disorders: results from the National Epidemiologic Survey on Alcohol and Related Conditions. Psychosom Med 2008;70:288-97.

9. Tang GX, Yan PP, Yan CL, et al. Determinants of suicidal ideation in gynecological cancer patients. Psychooncology 2016;25:97-103.

10. Tang NK, Beckwith $P$, Ashworth P. Mental defeat is associated with suicide intent in patients with chronic pain. Clin J Pain 2016;32:411-19.

11. Campbell G, Darke S, Bruno R, et al. The prevalence and correlates of chronic pain and suicidality in a nationally representative sample. Aust N Z J Psychiatry 2015;49:803-11.

12. Newton-John TR. Negotiating the maze: risk factors for suicidal behavior in chronic pain patients. Curr Pain Headache Rep 2014;18:447.

13. Timonen $\mathrm{M}$, Viilo $\mathrm{K}$, Hakko $\mathrm{H}$, et al. Suicides in persons suffering from rheumatoid arthritis. Rheumatology (Oxford) 2003;42:287-91.

14. Hirsch JK, Duberstein PR, Unützer J. Chronic medical problems and distressful thoughts of suicide in primary care patients: mitigating role of happiness. Int J Geriatr Psychiatry 2009;24:671-9.

15. Perera $\mathrm{S}$, Eisen $\mathrm{R}$, Bawor $\mathrm{M}$, et al. Association between body mass index and suicidal behaviors: a systematic review protocol. Syst Rev 2015;4:52.

16. Gao S, Juhaeri J, Reshef S, et al. Association between body mass index and suicide, and suicide attempt among British adults: the health improvement network database. Obesity (Silver Spring) 2013;21:E334-42.

17. Carpenter KM, Hasin DS, Allison DB, et al. Relationships between obesity and DSM-IV major depressive disorder, suicide ideation, and suicide attempts: results from a general population study. $A m$ Public Health 2000;90:251-7.

18. Farhat T. Stigma, obesity and adolescent risk behaviors: current research and future directions. Curr Opin Psychol 2015;5:56-66.

19. World Health Organization. Overweight and obesity. World Health Organization, 2015. http://www.who.int/gho/ncd/risk factors/ overweight/en/index1.html

20. KoreanEndocrineSociety. Management of obesity, 2010 recommendation. Endocrinol Metab 2010;25:301-4.

21. National Institute for Health and Clinical Excellence. Obesity: the prevention, identification, assessment and management of overweight and obesity in adults and children. NICE Clinical Guidelines. London: National Institute for Health and Clinical Excellence (UK), 2006.

22. Expert Panel on Detection, Evaluation, and Treatment of High Blood Cholesterol in Adults. Executive summary of the third report of the National Cholesterol Education Program (NCEP) expert panel on detection, evaluation, and treatment of high blood cholesterol in adults (Adult Treatment Panel III). JAMA 2001;285:2486-97.

23. Genuth $S$, Alberti KG, Bennett $P$, et al. Follow-up report on the diagnosis of diabetes mellitus. Diabetes Care 2003;26:3160-7.

24. Magnusson PK, Rasmussen F, Lawlor DA, et al. Association of body mass index with suicide mortality: a prospective cohort study of more than one million men. Am J Epidemiol 2006;163:1-8.

25. Mukamal KJ, Kawachi I, Miller M, et al. Body mass index and risk of suicide among men. Arch Intern Med 2007;167:468-75.

26. Kaplan MS, McFarland $\mathrm{BH}$, Huguet N. The relationship of body weight to suicide risk among men and women: results from the US National Health Interview Survey Linked Mortality File. J Nerv Ment Dis 2007;195:948-51.

27. Bjerkeset O, Romundstad P, Evans J, et al. Association of adult body mass index and height with anxiety, depression, and suicide in the general population: the HUNT study. Am J Epidemiol 2008;167:193-202.

28. Mukamal KJ, Rimm EB, Kawachi I, et al. Body mass index and risk of suicide among one million US adults. Epidemiology 2010;21: 82-6.

29. McCarthy JF, Ilgen MA, Austin K, et al. Associations between body mass index and suicide in the veterans affairs health system. Obesity (Silver Spring) 2014;22:269-76.

30. Austin $A E$, van den Heuvel $C$, Byard RW. Body mass index and suicide. Am J Forensic Med Pathol 2014;35:145-7.

31. Sörberg A, Gunnell D, Falkstedt D, et al. Body mass index in young adulthood and suicidal behavior up to age 59 in a cohort of Swedish men. PLOS ONE 2014;9:e101213.

32. Mukamal KJ, Wee CC, Miller M. BMI and rates of suicide in the United States: an ecological analysis. Obesity (Silver Spring) 2009;17:1946-50.

33. Batty GD, Whitley $\mathrm{E}$, Kivimäki $\mathrm{M}$, et al. Body mass index and attempted suicide: cohort study of 1,133,019 Swedish men. Am J Epidemiol 2010;172:890-9.

34. Dong C, Li WD, Li D, et al. Extreme obesity is associated with attempted suicides: results from a family study. Int $J$ Obes (Lond) 2006;30:388-90.

35. Falkner NH, Neumark-Sztainer D, Story M, et al. Social, educational, and psychological correlates of weight status in adolescents. Obes Res 2001:9:32-42.

36. Mather AA, Cox BJ, Enns MW, et al. Associations of obesity with psychiatric disorders and suicidal behaviors in a nationally representative sample. J Psychosom Res 2009;66:277-85.

37. van Wijnen LG, Boluijt PR, Hoeven-Mulder HB, et al. Weight status, psychological health, suicidal thoughts, and suicide attempts in Dutch adolescents: results from the 2003 E-MOVO project. Obesity (Silver Spring) 2010;18:1059-61.

38. Wagner B, Klinitzke G, Brähler E, et al. Extreme obesity is associated with suicidal behavior and suicide attempts in adults: results of a population-based representative sample. Depress Anxiety 2013;30:975-81.

39. Zeller MH, Reiter-Purtill J, Jenkins TM, et al. Adolescent suicidal behavior across the excess weight status spectrum. Obesity (Silver Spring) 2013;21:1039-45.

40. Dutton GR, Bodell LP, Smith AR, et al. Examination of the relationship between obesity and suicidal ideation. Int J Obes (Lond) 2013;37:1282-6.

41. Heneghan HM, Heinberg L, Windover A, et al. Weighing the evidence for an association between obesity and suicide risk. Surg Obes Relat Dis 2012;8:98-107. 
42. Klinitzke G, Steinig J, Blüher $M$, et al. Obesity and suicide risk in adults-a systematic review. J Affect Disord 2013;145:277-84.

43. Zhang J, Yan F, Li Y, et al. Body mass index and suicidal behaviors: a critical review of epidemiological evidence. J Affect Disord 2013;148:147-60.

44. Puhl RM, Heuer CA. Obesity stigma: important considerations for public health. Am J Public Health 2010;100:1019-28.

45. Kim S, So WY. Prevalence and sociodemographic trends of weight misperception in Korean adolescents. BMC Public Health 2014; $14: 452$.

46. Jun EM, Choi SB. Obesity, body image, depression, and weight-control behaviour among female university students in Korea J Cancer Prev 2014;19:240-6.

47. Schuler PB, Vinci D, Isosaari RM, et al. Body-shape perceptions and body mass index of older African American and European American women. J Cross Cult Gerontol 2008;23:255-64.
48. Wilfley DE, Schreiber GB, Pike KM, et al. Eating disturbance and body image: a comparison of a community sample of adult black and white women. Int J Eat Disord 1996;20:377-87.

49. Golomb BA, Tenkanen L, Alikoski T, et al. Insulin sensitivity markers: predictors of accidents and suicides in Helsinki Heart Study screenees. J Clin Epidemiol 2002;55:767-73.

50. Lawlor DA, Smith GD, Ebrahim S. Association of insulin resistance with depression: cross sectional findings from the British Women's Heart and Health Study. BMJ 2003;327:1383-4.

51. Jasienska G, Ziomkiewicz A, Górkiewicz M, et al. Body mass, depressive symptoms and menopausal status: an examination of the "Jolly Fat" hypothesis. Womens Health Issues 2005;15:145-51.

52. Kim JH, Park EC, Yoo KB. Effects of the gap between socioeconomic status and perceived social class on suicidal ideation: unique perspectives using a longitudinal analysis. Arch Gerontol Geriatr 2015;61:384-91. 